\title{
Movement Patterns of the Eastern Chipmunk (Tamias striatus) in Four Fragmented Landscapes of Prince Edward Island, Canada
}

\author{
Sheldon B. Opps ${ }^{1}{ }^{*}$, Leslie A. Cudmore ${ }^{2}$, Marina Silva-Opps ${ }^{3}$ \\ ${ }^{1}$ Department of Physics, University of Prince Edward Island, Charlottetown, Prince Edward Island, Canada \\ ${ }^{2}$ Office of the Vice President Academic and Research, University of Prince Edward Island, Charlottetown, \\ Prince Edward Island, Canada \\ ${ }^{3}$ Department of Biology, University of Prince Edward Island, Charlottetown, Prince Edward Island, Canada \\ Email: *sopps@upei.ca
}

How to cite this paper: Opps, S.B., Cudmore, L.A. and Silva-Opps, M. (2020) Movement Patterns of the Eastern Chipmunk (Tamias striatus) in Four Fragmented Landscapes of Prince Edward Island, Canada. Open Journal of Ecology, 10, 688-715.

https://doi.org/10.4236/oje.2020.1010042

Received: August 28, 2020

Accepted: October 27, 2020

Published: October 30, 2020

Copyright ( 2020 by author(s) and Scientific Research Publishing Inc. This work is licensed under the Creative Commons Attribution International License (CC BY 4.0).

http://creativecommons.org/licenses/by/4.0/ (c) (i) Open Access

\begin{abstract}
The analysis of animal movement patterns can provide important information on animals' responses to habitat features. In this study, the movement paths of eastern chipmunks (Tamias striatus) were examined in four landscapes, with different levels of habitat fragmentation, using either fluorescent powdering or spool-and-line tracking. Descriptions of the tree and ground vegetation communities were performed in the vicinity of the trail to obtain information on habitat use and habitat selection. Several key movement variables were calculated, including the total path length, net distance, fractal dimension, and radius of gyration. Despite statistically significant differences in some of the movement metrics between the four landscapes, the overall movement patterns were generically the same for all of chipmunk paths examined in this study. The data were compared to trends expected based on random or correlated random walks, as well as Lévy-walk models. The mean squared net displacement did not support the correlated random walk predictions, except at smaller spatial scales, but overall demonstrated Lévy-like super diffusive behaviour. Lévy-like patterns were also confirmed from the move-length distributions that demonstrated truncated-tail power-law behaviour. Although this would suggest invariance of the movement patterns at all spatial scales studied, fractal analysis revealed at least two transitions in movement patterns at scales of around 2 and $5 \mathrm{~m}$. The transition point at $2 \mathrm{~m}$ was negatively correlated with the density of small trees, while the transition at $\sim 5 \mathrm{~m}$ was positively correlated with the spatial distribution of large trees. As the habitat-preference data showed that small trees are among the least preferred habitat component, while large trees were among the most pre-
\end{abstract}


ferred habitat, chipmunks are likely to alter their movement behaviour to avoid small trees, and attracted towards large trees possibly to avoid predators. Overall, we determined three principal domains of movement: at smaller spatio-temporal scales, foraging activities dominate and the movement is highly correlated but also random; at intermediate spatial scales, chipmunks may be moving to avoid predators, using different environmental cues, and the movement is more directed (but still influenced by vegetation patterns at intermediate scales); at larger spatio-temporal scales, the movement is dominated by long-range/long-term memory and homing to burrows and other key habitat features, such as food caches, drives more directed movement. The fact that scale-dependent movement mechanisms could give rise to LW patterns is consistent with recent studies.

\section{Keywords}

Fluorescent Powder, Spool-and-Line, Fractal, Radius of Gyration, Lévy Walk, Correlated Random Walk, Small Mammals, Prince Edward Island

\section{Introduction}

Movement is an important aspect of an animal's behaviour that influences foraging, predation risk, and interactions with conspecifics and members of other species [1] [2] [3]. Many factors affect an animal's movement patterns, including habitat quality, resource availability and even anthropogenic features. For example, an animal may be positively influenced by finding a mate or encountering suitable habitat, but negatively affected if the habitat found is unsuitable, or if a predator is encountered (e.g., [4]). The sum of such influences on the individuals within a population ultimately affects population dynamics and the composition of the community [5].

Movement patterns are the result of complex behavioural responses to environmental factors and landscape features operating at different spatial scales [6]-[12]. At smaller temporal scales, animals move to accomplish daily basic activities such as foraging, defense of territories, finding mates, and care for offspring. Over longer time periods, animals perform movements at larger spatial scales that are related to dispersal, migration and colonization events. Additionally, habitat heterogeneity (i.e. the structural and compositional complexity of the habitat) may influence the decisions made by organisms when moving through their habitats, such as by impeding locomotion [13] [14], creating risks to movement [15], modifying foraging areas [16], enhancing protection against predators [16] [17], and increasing visual obstruction [18]. Movement paths for various animal species have been investigated with respect to habitat heterogeneity, including small mammals [8] [10] [12] [19]. For example, [19] found that at larger spatial scales wood mice (Apodemus sylvaticus) exhibited random movement as they moved among bushes, but at smaller spatial scales their 
movements were directed toward particular bushes. Similarly, [20] found deer mice (Peromyscus maniculatus) had straighter pathways in areas where shrubs were sparse, and then became more tortuous with increasing shrub cover. Another study showed that the short-tailed weasel (Mustela erminea) made more tortuous paths in foraging areas than in areas used exclusively as travel routes [10].

The responses of animals to habitat heterogeneity may also be affected by life history and innate behavioral characteristics of the organisms themselves including body size, perceptual range, home range, habitat specificity, predation risk, reproductive stage, and gender (e.g., [6] [9] [12] [19] [21]). Perceptual range represents the range at which an animal can perceive landscape elements and other habitat features [7] [22] [23] [24]. The typical perceptual range of a species may vary depending on the geometry and structural complexity of the habitat within which it moves [24] [25] For animals using vision as a primary tool to recognize or identify habitat features within their habitats, perceptual range can directly affect the spatial scale at which they respond to them. Hence, movement patterns may reflect differences in how organisms perceive habitat heterogeneity and its components over a given range of spatial scales. Studies on spatial memory and navigation also suggest that many animal species are capable of re-orienting themselves and re-tracing their paths using prior knowledge of specific locations within their home ranges [26] [27]. In particular, several studies have demonstrated the capacity of rodents to use visual landmarks such as habitat features (e.g., shrubs, trees) to direct their activities during the course of their movements within the home range [19] [28] [29] [30]. Although rodent species may vary with respect to this ability, one could predict that territorial species will make use of visual landmarks to reach different parts of their home range (e.g., territory) more frequently than non-territorial species. Since movement allows individuals to find food and mates, and avoid predators, an animal's movement pathway may also reflect the decisions made by the organism to optimize the success of these fundamental activities. For example, males of many mammalian species, including rodents, have larger home ranges and dispersal ranges than females because parental care is generally confined to females. It has also been found that small-mammal species tend to choose habitats that favour predator avoidance over food availability; hence, some resources are utilized to a greater extent than would be predicted from the availability of the resource [31] [32] [33].

Animal movement patterns have been examined using several models including random, correlated random, and biased random walks (e.g. [12] [34] [35] [36]). In addition, fractal analysis has often been used as a tool to study movement patterns. In the correlated random walk (CRW) model, the walker executes a "move" by randomly selecting the speed, duration (or length), and turning angle (angle between consecutive moves which is chosen relative to the direction of the previous step) of the move. Repeated application of this proce- 
dure produces a path that is characterized by three distributions: move speed, move size, and turning angle. Although the sampling from these distributions is both independent and random, there is a tendency for the movement to become directed due to correlations between the turning angles [34] [35]. Consequently, CRW has been used to describe random movements with a certain level of directionality (e.g. [12] [37] [38]).

Another model that has been used to describe the movement of many organisms (e.g., amoeba, spider monkeys, jackals, etc.) is the Lévy walk (LW) model [27] [36] [39] [40] [41]. LW can be described as a biased random walk characterized by the presence of rare but extremely large "jumps" [42]. The distributions of move lengths for LW do not fall off as rapidly at long distances as compared to Gaussian distributions. The small jumps are interspersed with longer jumps causing the variance of Lévy distributions to diverge in contrast to the finite variance observed in the random walk model. As a result, Lévy trajectories describe distributions with longer, power-law tails. The LW model shows spatial-scale invariance in both the length of constituent steps and the duration between steps [43]. In the LW model, the net squared displacement from the point of release of the walker increases with time more rapidly as compared with the random walk or correlated random walk models, resulting in what physicists call "anomalous" or "super" diffusion. This suggests that the LW model may describe an efficient way of covering large regions of space, especially when compared to random motion [44].

Another method that is commonly employed to study animal movement patterns is fractal analysis (FA), which has been traditionally used to quantify patterns, processes, or objects of irregular form. Two properties of fractals are important when describing animal movement. First, fractals can have non-integer dimensions, characterized by the fractal dimension $(D)$, contrary to Euclidean geometry [45]. For example, $D$ for movement paths varies between 1 when the path is straight and 2 when the path is so tortuous as to completely cover a plane. Hence $D$ provides a means of assessing path complexity or tortuosity. Second, most fractal structures found in nature possess self-similarity across a range of spatial scales, meaning that the pattern observed at smaller spatial scales is reproduced at larger spatial scales. Consequently, if a movement path exhibits fractal behaviour, then the value for $D$ obtained at smaller measurement scales will be the same value as that obtained at larger scales, and hence will be a scale-independent measure [46]. However, before $D$ can be used as a descriptor of the tortuosity or complexity of a movement pathway, it must first be demonstrated that it does not change over the range of spatial scales examined [46] [47], or else the use of one value of $D$ for the whole pathway is invalid. Nonetheless, changes in $D$ can still be informative, since such scale-dependent shifts in a pattern may be indicative of a transition in processes that regulate the observed patterns [48]. This suggests that $D$ can be used as a tool to examine the scales at which the animal's response to its environment changes. 
Eastern chipmunks (Tamias striatus) are habitat specialists [49], suggesting that habitat features (and disturbances that affect the structure of the habitat) can influence their decisions when moving within their home range. They have relatively small home ranges, generally less than 0.50 ha [50]-[55], and defend small territories or core areas (15 - $25 \mathrm{~m}$ in radius) around their burrows. However, eastern chipmunks are also known to make longer movements $(>50 \mathrm{~m})$ for exploration and dispersal through open fields or fencerows [49] [52] [56]. Therefore, we predict that at smaller spatial scales eastern chipmunks will use familiar landmarks (e.g., trees, shrubs) to orient themselves during the course of their daily movements. At larger spatial scales, the movements of eastern chipmunks may be more influenced by the overall structural complexity of the habitat. Since different types of vegetation will exhibit different fractal patterns, an animal's interaction with the different types of vegetation will be reflected by changes in fractal dimension. Finally, given that eastern chipmunks are diurnal animals that rely heavily on their vision [55], we also hypothesize that their movement is ultimately governed by the coupling between innate behaviour and habitat characteristics over multiple spatial and temporal scales.

The main purpose of this study was to investigate the movement patterns of the eastern chipmunk in four landscapes in Prince Edward Island (Canada), with each landscape varying in the level of fragmentation and habitat structure. Although CRW and LW models were employed as "null-hypotheses" models of scale-independent movement, we predicted scale-dependent variation in the relationships between movement metrics and habitat features. The FA of the movement patterns did reveal transitions in movement at different spatial scales, supporting the importance of a multiscale approach when studying the movement patterns of animals inhabiting fragmented landscapes.

\section{Methods}

\subsection{Study Sites}

This study was conducted from May to October 2002 in central Prince Edward Island (PEI), Canada. Four study sites (Figure 1) that varied in their habitat-fragmentation level were identified using ArcView: GIS (version 8.1) with the 2000/02 PEI Corporate Landuse Inventory. Habitat fragmentation variables used to differentiate study sites were the size of the forest patches, the area of surrounding agricultural fields, and the presence of hedgerow connections between forest patches. Sites consisted of continuous forest, with virtually no surrounding agriculture within a $1000 \mathrm{~m}$ radius (Brackley), small connected patches of forest within an agricultural surrounding (Morell), various-sized connected patches of forest within an agricultural surrounding (Pleasant Grove), and various-sized unconnected patches of forest within an agricultural surrounding (Cavendish). All four sites were fragmented approximately 50 - 60 years ago, and are now surrounded by agricultural fields that were part of two-year potato and hay rotations. 


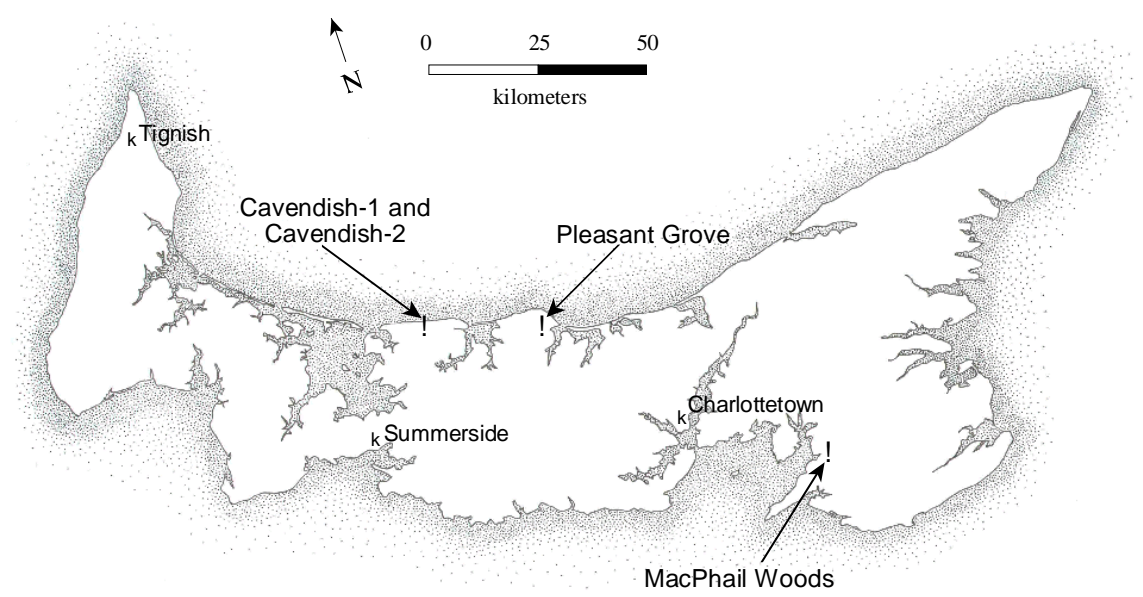

Figure 1. Map of Prince Edward Island (Canada) indicating two main towns (stars) and the location of the four agricultural landscapes examined in this study.

\subsection{Capture, Handling and Data Collection}

At each study site, we established trapping grids that covered about $10 \%$ of the forest-patch area. Trapping grids consisted of trapping stations (1 Sherman live-trap per trapping station) spaced $10 \mathrm{~m}$ apart [57] with traps baited with either sunflower seeds or a mixture of peanut butter and rolled oats. Captured eastern chipmunks were ear-tagged (Monel 1 ear-tags), sexed and weighed with Pesola scales $( \pm 2 \mathrm{~g})$ (sensu [56]). Only animals that had no external wounds, disfigurements, and that were not pregnant or lactating, were used for movement experiments. Movement data were obtained using two methods: fluorescent powdering [29] and spool-and-line tracking [58]. We initially decided to use fluorescent powdering because it was assumed that this technique could provide fine-scale information on the movement made by the individual [29]. Prior to their release, the animal's body was brushed with fluorescent powder (Radiant ${ }^{\mathrm{TM}}$ fluorescent pigment), so its precise trajectory through the habitat could be tracked the next evening using a hand-held ultraviolet light. Subsequently, each animal trail was re-traced with pink flagging tape. Unfortunately, after using this technique for a few days, we realized that the tracking of several paths during one evening was tremendously time-consuming. Therefore, we decided to replace this technique with the spool-and-line tracking [59] which was originally not used in this study because of concern that the line would not catch well in areas without ground cover objects or trees. After conducting some field tests, we concluded that the spool-and-line tracking technique was not only less time-consuming, but it produced equivalent quality data than the fluorescent powder technique. The spool-line technique involved the attachment (using cyanoacrylate glue) of a small balloon ( $15 \mathrm{~mm}$ in diameter) containing a spool of thread (180 $\mathrm{m}$ in length weighing $\sim 25 \mathrm{mg}$ ) to the upper back of the chipmunk before it was released. The thread snagged on objects on the forest floor as the chipmunk moved, leaving a continuous trail that could be re-traced with flagging tape any time of the day. 
We recorded data on habitat features (Table 1) surrounding each chipmunk's trail at both the microhabitat and the macrohabitat levels. For each movement path, we collected microhabitat data using $1 \mathrm{~m} \times 1 \mathrm{~m}$ plots located both along the path, and $2 \mathrm{~m}$ away from the path (on alternating sides) at $5 \mathrm{~m}$ intervals. The macrohabitat structure around the movement path was recorded by gathering data in $5 \times 5 \mathrm{~m}$ plots at intervals of $25 \mathrm{~m}$.

Table 1. Microhabitat and macrohabitat features associated with the movement pathways of the eastern chipmunks.

\begin{tabular}{|c|c|}
\hline Habitat variable & Description \\
\hline \multicolumn{2}{|l|}{ Microhabitat } \\
\hline Soil temperature & Soil temperature using a digital thermometer $\left({ }^{\circ} \mathrm{C}\right)$ \\
\hline Soil moisture & $\begin{array}{l}\text { Soil moisture using a meter that quantifies moisture on a } \\
\text { continuous scale from } 1 \text { (very dry) to } 10 \text { (very wet) }\end{array}$ \\
\hline Canopy cover & $\begin{array}{l}\text { Percent canopy above the midpoint of the microhabitat plot using } \\
\text { a spherical densitometer }\end{array}$ \\
\hline Small trees & Percent of plot covered by trees less than $5 \mathrm{~m}$ in height \\
\hline Medium trees & Percent of plot covered by trees 5 to $10 \mathrm{~m}$ in height \\
\hline Tall trees & Percent of plot covered by trees more than $10 \mathrm{~m}$ in height \\
\hline Ground cover & $\begin{array}{l}\text { Average } \% \text { cover each of trees, shrubs, grass, moss, herbs, and } \\
\text { vines, logs, stumps, and other woody debris }\end{array}$ \\
\hline Evenness of living ground cover & Smith and Wilson evenness ${ }^{\mathrm{a}}$ of the classes of living ground cover \\
\hline $\begin{array}{l}\text { Evenness of non-living ground } \\
\text { cover }\end{array}$ & $\begin{array}{l}\text { Smith and Wilson evenness }{ }^{\mathrm{a}} \text { of the classes of non-living ground } \\
\text { cover }\end{array}$ \\
\hline \multicolumn{2}{|l|}{ Macrohabitat } \\
\hline Small tree density & Density (per $\mathrm{m}^{2}$ ) of trees less than $5 \mathrm{~m}$ in height \\
\hline Medium tree density & Density (per $\mathrm{m}^{2}$ ) of trees 5 to $10 \mathrm{~m}$ in height \\
\hline Large tree density & Density (per $\mathrm{m}^{2}$ ) of trees greater than $10 \mathrm{~m}$ in height \\
\hline Stump density & Density $\left(\right.$ per $\left.\mathrm{m}^{2}\right)$ of stumps \\
\hline Log density & Density $\left(\right.$ per $\left.\mathrm{m}^{2}\right)$ of logs \\
\hline Dead tree density & Density $\left(\right.$ per $\mathrm{m}^{2}$ ) of dead trees \\
\hline Tree circumference & Average tree circumference (at breast height) \\
\hline Evenness of tree species & Smith and Wilson evenness ${ }^{\mathrm{a}}$ of trees \\
\hline
\end{tabular}

${ }^{\text {a }}$ Calculated using the software Ecological Methodology [92].

\subsection{Movement Metrics and Analyses}

Movement paths were recorded with a Sony ${ }^{\oplus}$ DCR-TRV530 digital video camera as a sequence of digital pictures. As pictures were taken at different heights and orientations, fluorescent markers of fixed length $(25 \mathrm{~cm})$ were placed at $1 \mathrm{~m}$ intervals along the paths and oriented in the same cardinal direction in order to establish a calibration standard for subsequent movement-path processing and analysis. Using Paint Shop Pro, v. 7., each picture was corrected (rescaled and 
reoriented) to the calibration settings and then merged together to reconstruct the original movement path. SigmaScan Pro 5 was then used to obtain $x y$ coordinates of each movement path, correctly scaled against the calibration settings, in order to calculate movement metrics and other statistical analyses used in this study. Note that to take into consideration the time usually required for an animal to move away from the researcher and/or reorient itself after being released, we excluded from the analyses the first $10 \mathrm{~m}$ of the path.

A number of complementary metrics were utilized to characterize individual paths and explore movement behaviour. The program VFractal [60], which has been used in various studies to analyze animal movement paths (e.g., [3] [10] [46] [61]), was used to directly obtain a number of these movement metrics, including the total path length $(\mathrm{m})$, the mean cosine of the turning angles (formed by changes in direction among steps) and associated variance, and the net displacement (the straight-line distance between the starting and end points of the path; $\mathrm{m}$ ). Additional analysis was performed using the program AMAP (Animal Movement Analysis Program), a software package developed by one of the authors (S.B. Opps ${ }^{4}$ ). A number of metrics were obtained from this program based on the following equations. A tortuosity factor was calculated as the ratio of the net displacement divided by the total path length (sensu [8]),

$$
\xi=\frac{\left|\boldsymbol{R}_{E E}\right|}{\sum_{i=1}^{N}\left|\boldsymbol{R}_{i}\right|},
$$

where $\boldsymbol{R}_{E E}$ is the end-to-end vector and $\left|\boldsymbol{R}_{i}\right|$ is the length of each path segment (or step). This ratio will vary between 0 (no displacement) to 1 (path is a straight line). We also examined the effective size or shape of the movement paths using the radius of gyration $\left(R_{g}\right)$, a tool commonly used in polymer physics [62], which is defined as

$$
R_{g}^{2}=\frac{1}{N} \sum_{i=1}^{N}\left\langle\left(\boldsymbol{R}_{i}-\boldsymbol{R}_{C M}\right)^{2}\right\rangle,
$$

where $\boldsymbol{R}_{i}$ gives the position of a particular segment along the path relative to some origin and $\boldsymbol{R}_{C M}$ denotes the center-of-mass position defined as,

$$
\boldsymbol{R}_{C M}=\frac{1}{N} \sum_{i=1}^{N} \boldsymbol{R}_{i} .
$$

According to Flory's mean-field theory for polymers [63], both $R_{g}$ and $R_{E E}$ demonstrate the following scaling behaviour,

$$
R_{g} \sim N^{v}
$$

where $N$ is the total number of segments along the polymer chain and $v$ is the Flory exponent that depends on the solvent conditions. In particular, under "good" solvent conditions where the polymer interacts favourably with the solvent molecules, $v=3 / 5$ and the chains are more stretched out and elongated. Under "poor" solvent conditions, $v=1 / 3$, and the polymer is more compact. In the current context, we predict that in good habitat under favourable foraging 
conditions, movement paths will be more compact and $R_{g}$ will scale closer to $v=$ 1/3. In contrast, in poor habitat (when searching for good habitat) or when avoiding predation, the movement paths will be more extended and $R_{g}$ will then scale as $v=3 / 5$.

A number of theoretical random-walk models were employed to examine if they explained the observed movement patterns. The CRW model was tested for agreement by comparing the observed mean squared net displacement (MSND), $\overline{R_{n}^{2}}$ of movement paths at step $n$ with predictions based on the CRW model, $\mathrm{E}\left(\overline{R_{n}^{2}}\right)$, as provided by the following equation developed by [34] (for the case of symmetric distribution of the turning angle),

$$
\begin{aligned}
\mathrm{E}\left(\overline{R_{n}^{2}}\right) & =n l_{2}+2 l_{1}^{2} \frac{c}{1-c}\left(n-\frac{1-c^{(n-1) / 2}}{1-c}\right) \\
& \approx n\left(l_{2}+2 l_{1}^{2} \frac{c}{1-c}\right), \text { for } n \gg 1
\end{aligned}
$$

where again $n$ denotes the number of consecutive steps along the path, $l_{1}$ is the mean move length (over $n$ steps), $l_{2}$ is the mean of the move length squared (or second moment), and $c$ is the mean cosine of the turning angle. Values for both $\overline{R_{n}^{2}}$ and $\mathrm{E}\left(\overline{R_{n}^{2}}\right)$ were obtained using the Vfractal program and comparisons were conducted using the conventional approach of pooling all paths together [35], as well as by examining paths from each study site separately. For pooled data, we could compare observed with expected values, at a given number of consecutive steps, using a chi-squared test. For an overall comparison based on all $n$, we used a test statistic developed by [64],

$$
R_{\text {Diff }}=\frac{1}{k} \sum_{n=1}^{k} \frac{\overline{R_{n}^{2}}-\mathrm{E}\left(\overline{R_{n}^{2}}\right)}{\mathrm{E}\left(\overline{R_{n}^{2}}\right)},
$$

with associated variance given by the estimate,

$$
\hat{\sigma}_{R_{\text {Diff }}}^{2}=\frac{1}{k^{2}} \sum_{n=1}^{N} \sum_{m=1}^{N} \frac{\text { s.e. }\left(R_{n}^{2}\right) \text { s.e. }\left(R_{m}^{2}\right)}{\mathrm{E}\left(\overline{R_{n}^{2}}\right) \mathrm{E}\left(\overline{R_{m}^{2}}\right)} .
$$

$R_{\text {Diff }}$ is normally distributed and, under the null hypothesis of a correlated random walk, the expected value is zero. Thus, $z$-values could be calculated as, $\mathrm{Z}=R_{\text {Diff }} / \hat{\sigma}_{R_{\text {Diff }}}^{2}$, to test for statistical significance. To complement these calculations, we also compared the slopes of the curves of $\overline{R_{n}^{2}}$ and $\mathrm{E}\left(\overline{R_{n}^{2}}\right)$ using a standard t-test with a Bonferroni correction. To substantiate the CRW computations, the persistence and directionality of movement paths were also evaluated, including a comparison between the distribution of the cosines of the turning angles and a uniform distribution using the Shapiro-Wilk test.

The LW model predicts that the MSND will grow faster in time than that of random walk because of the possibility for the walker to take larger steps. Consequently, Lévy walks are "super diffusive" and the MSND satisfies a power-law function of the time, $t$, of the form: 


$$
\overline{R^{2}(t)} \sim t^{-\alpha} \text {, where } 1<\alpha<2
$$

To test whether movement paths followed the LW model, we examined the relationship between mean squared net displacement and consecutive steps given that the time of travel is proportional to a movement step. The relationship between these two variables (mean squared net displacement and consecutive steps) was tested for a power-law relationship by examining their log-log relationship using linear regression analysis. Values of slopes were recalculated using a reduced major axis. Variations in movement paths due to gender or habitat (i.e., study site) that may be revealed by this model were examined by comparing the slope of the log-log relationships using a t-test for regression slopes with Bonferroni correction when dealing with multiple comparisons. Another signature of an LW walk is that the truncated-tail move-length distribution satisfies a power-law relationship [43] [44] of the form:

$$
P(l) \sim l^{-\mu} \text {, where } 1<\mu<3
$$

Thus, although the existence of very large moves is rare, there is still a finite probability of observing infrequent larger-length moves as there is no intrinsic move-length scale-it is scale-free (or fractal-like). For example, it may be profitable for an organism to occasionally be making larger moves in situations where resources are scarcely distributed.

Fractal analysis is another tool frequently used to probe for scale-free movement behaviour; however, caution must be employed because $D$ is not necessarily constant over all spatial scales for a given movement path, as the patterns are not always self-similar, and so a single value of $D$ cannot be used to describe the complete movement pattern [35] [46]. Nonetheless, changes in D may indicate transitions in movement behavior that can provide important information about how animals respond to their environment at different spatial scales [5] [65]. As we were unable to identify constant values of $D$ over all spatial scales from our fractal analysis of movement paths in this study, we used $D$ as a probe to identify transitions in movement; we compared $D$ between study sites, and also between sexes, to identify transitions in movement at certain spatial scales separated by domains where $D$ remained scale invariant. We first examined the relationship between total path length and the log of step size using locally weighted sequential smoothing (LOESS; [66]) in SAS. A non-linearity of the relationship between these two variables was used as an indicator that $D$ changed with the spatial scale. Transitions were identified with LOESS at locations where there was a significant change in the slope of the relationship between total path length and log of step size. As suggested by [47], slopes of these relationships were recalculated using a reduced major axis. Fractal dimensions of each domain were computed using the formula provided by [67],

$$
L=S^{1-D}
$$

where $L$ is the total path length, $s$ is the step size, and $D$ is the fractal dimension. For each path, we compared $D$ among domains using t-test for slopes and Bon- 
ferroni correction when paths had more than two domains.

\subsection{Microhabitat and Macrohabitat Metrics and Analyses}

All microhabitat and macrohabitat variables were tested for normality (Shapiro-Wilk test) and transformations were performed when needed. Relationships between movement metrics and both microhabitat and macrohabitat characteristics were first assessed using Pearson correlation analysis. In an effort to determine underlying meaningful interactions among habitat variables, principal component analysis (PCA) was performed for microhabitat and macrohabitat variables separately. Habitat variables were entered into the PCA and important composite (PC) axes were retained. Importance was defined operationally by evaluating eigenvalues, considering only those $>1$ [68], and by a scree plot (looking for an inflection in the magnitude of eigenvalues arranged in decreasing order). In an effort to develop equations to predict variability in movement metrics, the relationship between movement metrics and PC axes were examined using stepwise multiple regression analysis. All statistical analyses were performed using SAS.

Habitat preference in the eastern chipmunk was examined using a rank preference index developed by [69]. For each chipmunk, thirteen habitat classes were ranked in terms of both use and availability (Table 1). To assess habitat use, the average percentage of each ground-cover class used along a pathway was determined using the information on microhabitat variables. Habitat availability was quantified by determining the average percentage of each ground-cover class available based on the microhabitat descriptions surrounding the pathways. For each class, the difference between the usage and availability was determined and ranked from the greatest to the least usage (termed the rank difference). Using information from all animals combined, the rank differences for each class were averaged. Using these average values, the habitat cover classes could then be sorted, with the smallest average rank being the most preferred class [69]. Significant differences among habitat classes (i.e., if eastern chipmunks significantly preferred certain classes over others) were examined using the Hotellings $\mathrm{T}^{2}$ test (sensu [69]) in conjunction with the Bayesian decision procedure [70].

\section{Results}

We obtained 32 movement paths of eastern chipmunks in four fragmented landscapes. Out of these 32 paths, 14 were obtained using the fluorescent powder technique and 18 were collected via the spool-and-line technique. Paths obtained with the fluorescent powder technique (mean length $=23.4 \pm 15.2 \mathrm{~m}$ ) were significantly shorter $(t=2.374 ; p=0.0242)$ than those obtained with the spool-and-line technique (mean length $37.9 \pm 19.3 \mathrm{~m}$ ). However, no other significant differences in movement metrics between these two techniques were observed during this study. Therefore, the rest of the analyses were conducted by pooling together the paths obtained with both techniques (sensu [46]). Statistical 
analyses examining the total path length were conducted using a dummy variable that distinguished between the two techniques.

It should be noted that although we did find statistically significant differences between the four landscapes for the various quantities investigated in this study, the movement patterns were generically very similar and exhibited common features; hence, we also include here findings obtained when all of the movement paths were pooled together from all four landscapes.

\subsection{Comparison with the CRW Model}

When pooling together all of the movement paths, t-test analyses showed that $\overline{R_{n}^{2}}$ differed significantly from the expected value $\mathrm{E}\left(\overline{R_{n}^{2}}\right)$ according to a CRW model $\left(R_{\text {Diff }}=3.2923 ; n=32 ; p=0.0001\right.$; Figure 2$)$. When paths were examined individually, 18 of the 32 paths differed significantly $(\mathrm{p}<0.05)$ from the expected value $\mathrm{E}\left(\overline{R_{n}^{2}}\right)$ based on the CRW model. Interestingly, all the paths collected in Brackley $(n=7)$ followed the CRW model, whereas all those collected in Morell $(n=8)$ differed significantly from the CRW model. Paths also differed significantly from the CRW model when examining females (t-test; $R_{\text {Diff }}=$ $2.6539 ; n=12 ; p=0.0001)$ and males (t-test; $R_{\text {Diff }}=3.7434 ; n=20 ; p=0.0001$ ) separately. The distribution of the mean cosine of turning angles of all individuals pooled together was non-uniformly distributed $(p=0.0150)$, suggesting directionality in the movement. However, we observed a difference in the distribution of the mean cosine of turning angles among study sites when examining them separately. The distribution of the mean cosine of turning angles was non-uniformly distributed for Cavendish $(p>0.05)$, Morell $(p>0.05)$, and Pleasant Grove $(p>0.05)$, but was uniformly distributed in Brackley $(p<0.05)$.

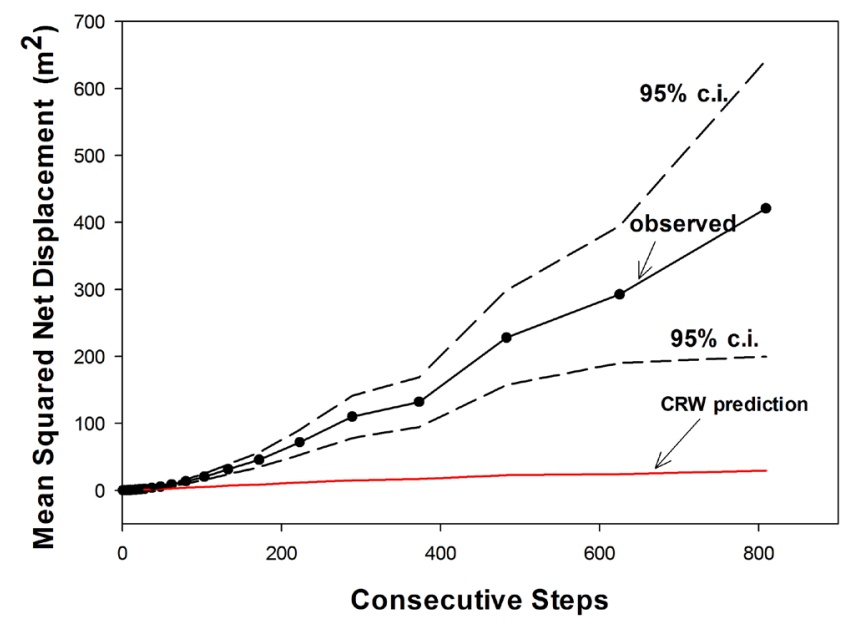

Figure 2. The difference between the observed mean squared net displacement for the eastern chipmunk compared to that predicted for a correlated random walk (CRW). It is clear that the observations (circles connected by solid black line) do not match with predictions based on the CRW model (solid red line), since the theoretical curve falls outside of the $95 \%$ confidence intervals (dashed lines) associated with the observed data. 


\subsection{Comparison with the LW Model}

The relationship between MSND and consecutive steps was well fit by a power-law function with an estimated value for the exponent of 1.68 ( $\mathrm{SE}=0.02 ; r^{2}=$ 0.98; Figure 3A). However, there were significant differences (t-tests for slopes; $p<0.05)$ in the value of the exponent among study sites when examined separately (Figure 3B). The exponent was $1.58\left(\mathrm{SE}=0.02 ; r^{2}=0.99\right)$ in Brackley, 1.63 $\left(\mathrm{SE}=0.03 ; r^{2}=0.99\right)$ in Cavendish, $1.81\left(\mathrm{SE}=0.01 ; r^{2}=0.99\right)$ in Morell, and 1.75 $\left(\mathrm{SE}=0.03 ; r^{2}=0.99\right)$ in Pleasant Grove. The log-log relationship of MSND and consecutive steps also demonstrated power-law behavior with exponent values of 1.63 for females and 1.74 for males. This is consistent with the fact that males cover significantly larger regions of space than females ( $\mathrm{t}$-test for slopes; $p<$ 0.05). Note that all of the exponents obtained in the MSND analysis obeyed the scaling behavior expected for the LW model (see Equation (2.8)), with the scaling exponents, $\alpha$, ranging between $1-2$.
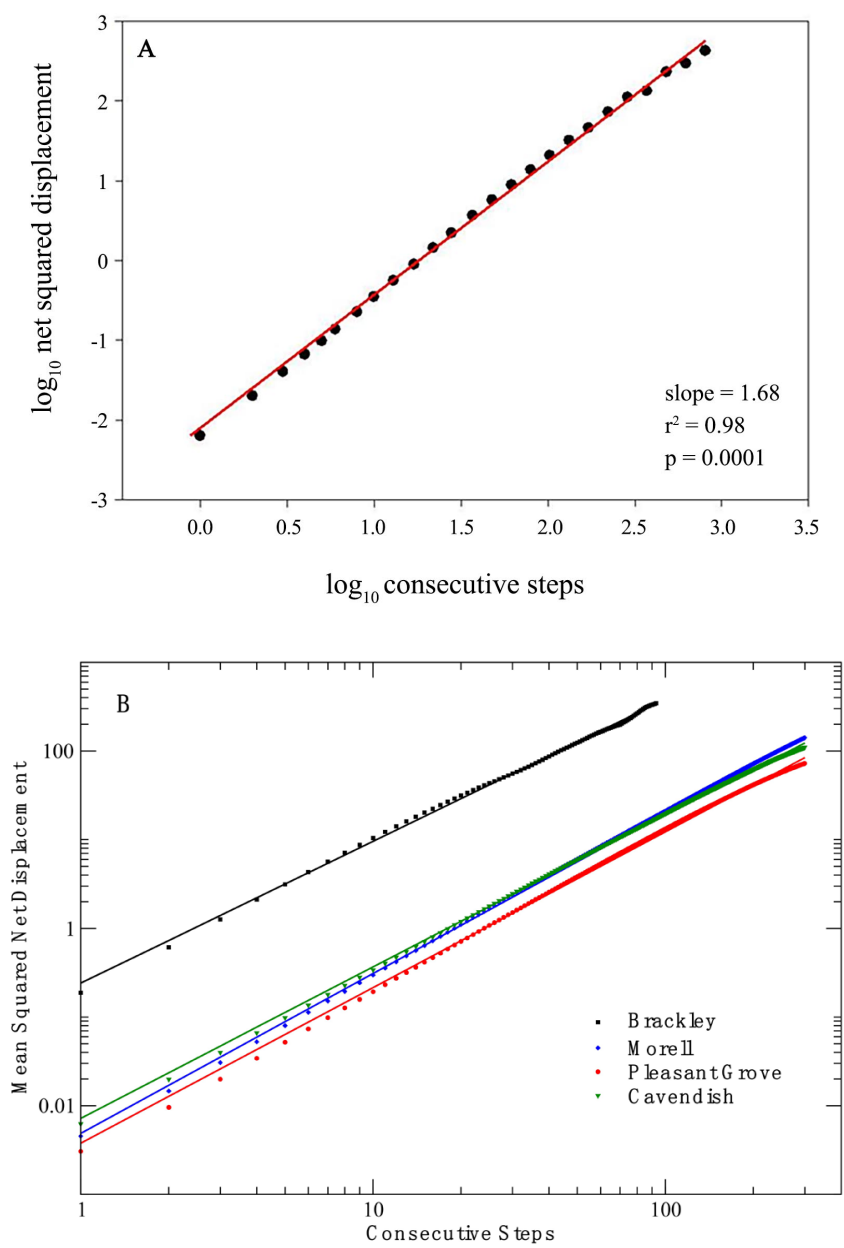

Figure 3. Log-log plots of the mean squared net displacement versus the number of consecutive steps: A. A graph for the pooled paths of the eastern chipmunk, the resultant power-law behavior demonstrates Lévy-like movement patterns. B. Graphs for each of the four study sites exhibit power-law relationships characteristic of Lévy-like movement patterns, with scaling exponents $\alpha$ falling in the range $1-2$. 
A complementary scaling analysis was conducted for the LW model by examining the move-length distribution. As noted in the literature [44] [71], it is preferable to use the cumulative or survival distribution for this kind of analysis due to the noisy features at larger move lengths due to sampling errors. When constructing histograms to explore power-law relationships, such as in Equation 2.9, there is always the challenge of determining the optimal bin width. As well, binning of data tends to lose finer-grained information about the data as individual values are lumped together within a given range [71]. By instead calculating the cumulative distribution function, no binning of the data is required and no information is lost, so a more complete and accurate picture emerges. In Figure 4, it is demonstrated that the tails of the survival move-length distributions are roughly linear on a log-log plot, as determined by regression analysis (except for Cavendish, which had an $r^{2}$ value of 0.92 , the other three sites had $r^{2}$ values of $\sim 0.99$ ). Thus, power-law behavior (Equation (2.9)) is exhibited for all of the landscapes studied, with the scaling exponents, $\mu$, falling within the $2-3$ range as predicted for the LW model [43] [44]. Naturally, it is impossible to avoid statistical noise in the tail extremes, due to the limitations of sample size.

The radius of gyration, $R_{g}$, demonstrated similar scaling behavior (Equation (2.4)) as the MSND (Figure 5). The Flory exponent, $v$, ranged from 0.742 for Brackley to 0.892 for Morell with Cavendish and Pleasant Grove falling in between with values of 0.841 and 0.855 , respectively. Again, although there were measurable differences between the four different study sites, with Brackley clearly standing out from the other landscapes, the overall trends were very similar.

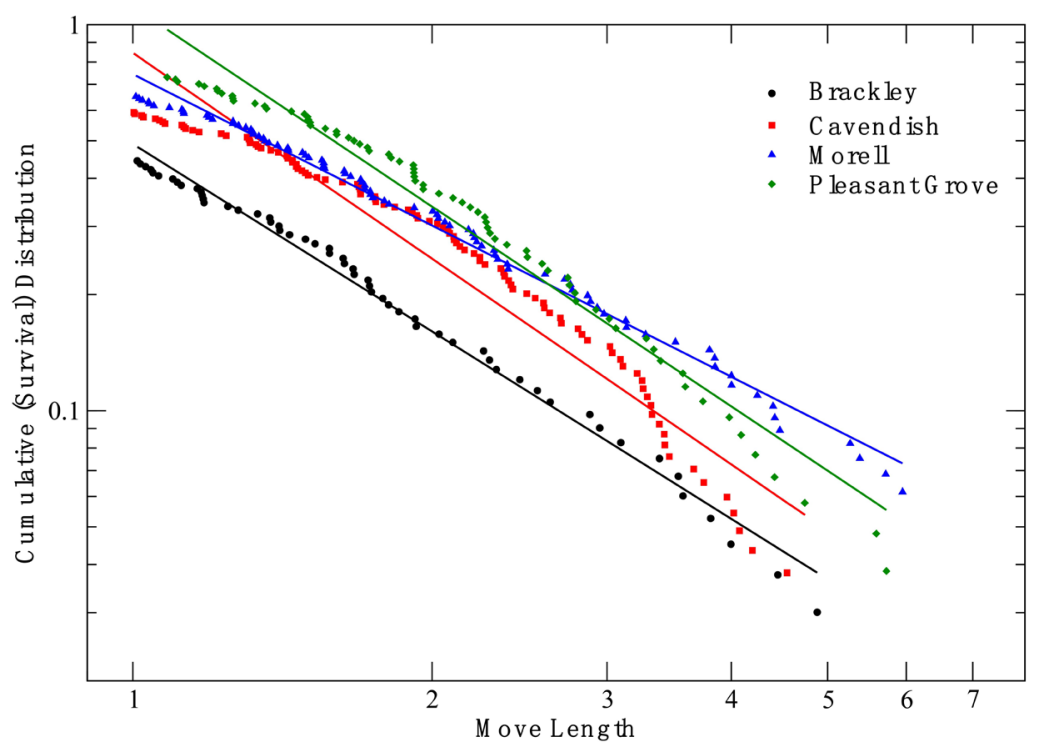

Figure 4. A log-log plot of cumulative (survival) distributions of move lengths for each of the four study sites. The resultant heavy-tail power-law behavior, with scaling exponents $\mu$ falling in the range 1 - 3, demonstrates Lévy-like movement patterns for all of the study sites. 


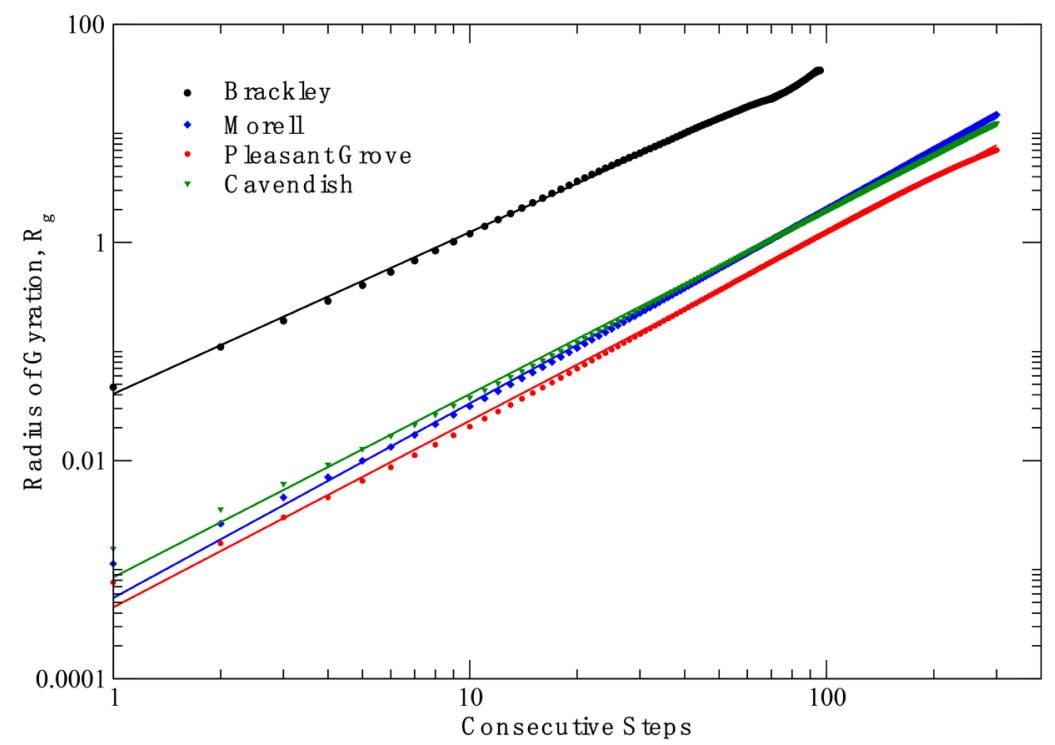

Figure 5. A log-log plot of the radius of gyration as a function of the number of consecutive steps. for each of the four study sites. The Flory exponent, $v$, ranged from 0.742 for Brackley to 0.892 for Morell with Cavendish and Pleasant Grove falling in between with values of 0.841 and 0.855 , respectively.

\subsection{Fractal Analysis}

All animal movement paths consistently exhibited marked changes in fractal dimension $(D)$, suggesting a scale-dependency for $D$. The examination of the log-log relationship between total path length and step size (ruler length along the path) for each of the four landscapes consistently showed $1-3$ transitions in $D$, as indicated by the change in slope (Figure 6A). Again, as the generic movement behaviour was similar across all landscapes, all animal paths were pooled together and the fractal analysis revealed changes in $D$ at $2.1 \mathrm{~m}$ and $7.6 \mathrm{~m}$ (Figure 6B). Transitions in $D$ were also detected when examining the log-log relationship between total path length and step size of individual paths. All movement paths revealed a transition in $D$ at approximately $2.0 \pm 1.2 \mathrm{~m}(n=$ 32). In addition, 21 paths showed a second transition in $D$ at $5.9 \pm 1.4 \mathrm{~m}$, and 8 paths showed a third transition in $D$ at approximately $12.7 \pm 1.2 \mathrm{~m}$. The number of transitions observed per path was significantly related to path length (ANOVA; $p=0.0015$; Figure 7). These transitions in $D$ defined two domains in movements for 11 individuals, three domains for 13 individuals, and 4 domains in movements for 8 other individuals. For each path, we calculated $D$ for each domain when enough data were available to conduct regression analysis. Averaging $D$ over all paths gave us the following results: $1.107 \pm 0.132(n=27), 1.175$ $\pm 0.184(n=31), 1.437 \pm 0.514(n=20)$, and $1.087 \pm 0.107(n=8)$ for the first, second, third, and fourth domains, respectively. $D$ differed significantly between the first and second domain in 22 out 27 paths (t-test, $p<0.05$ ). Significant differences in $D$ between the second and third domain were found in 18 out of 20 paths $(p<0.05)$. 

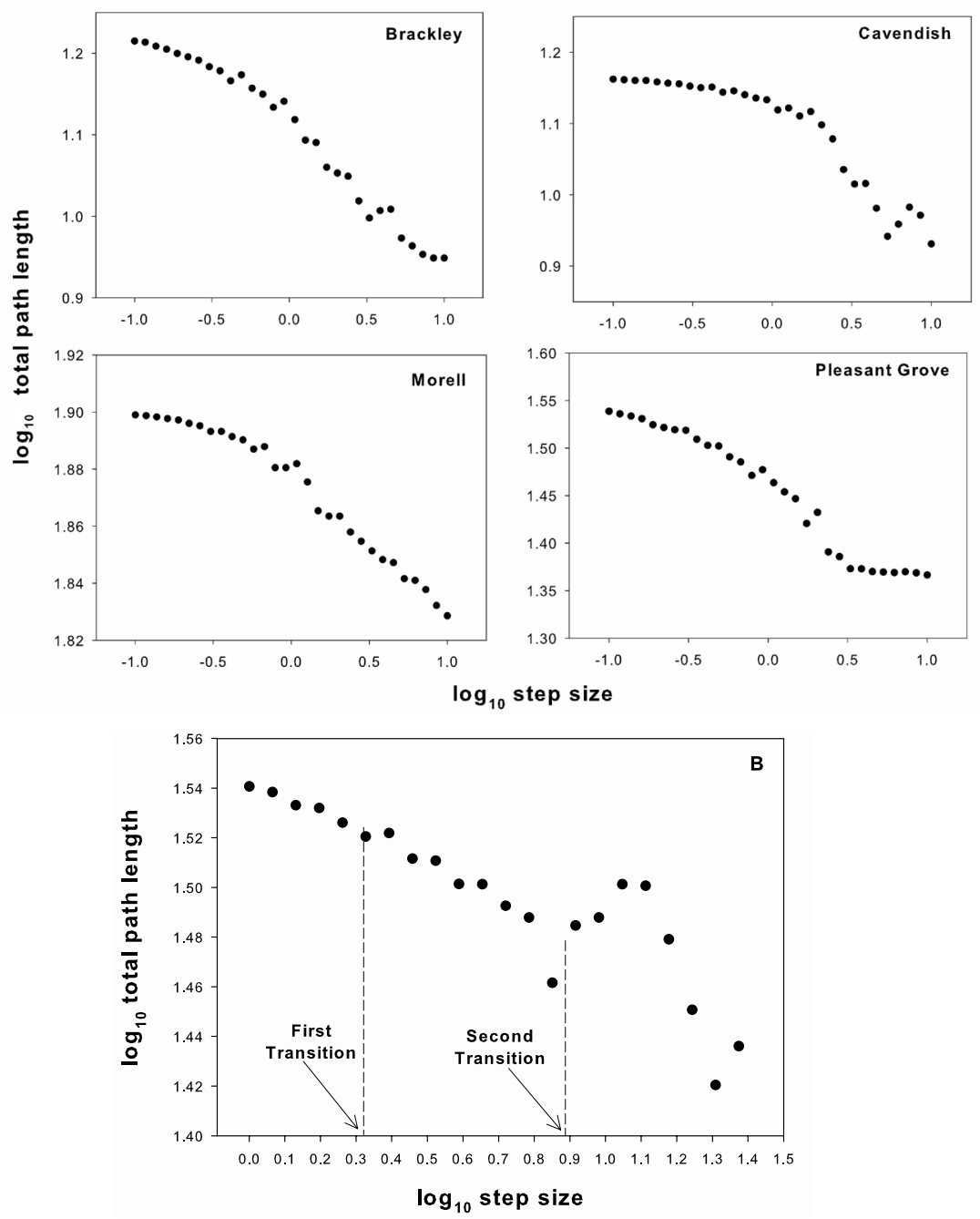

Figure 6. Log-log plots of the total path length as a function of the step size (ruler length along the path): A. Graphs for each of the four study sites demonstrate changes in the slope, and hence changes in the fractal $\mathrm{D}$, corresponding to $1-3$ transitions in movement patterns. B. A graph of the pooled data where fractal analysis revealed changes in D at 2.1 $\mathrm{m}$ and $7.6 \mathrm{~m}$.

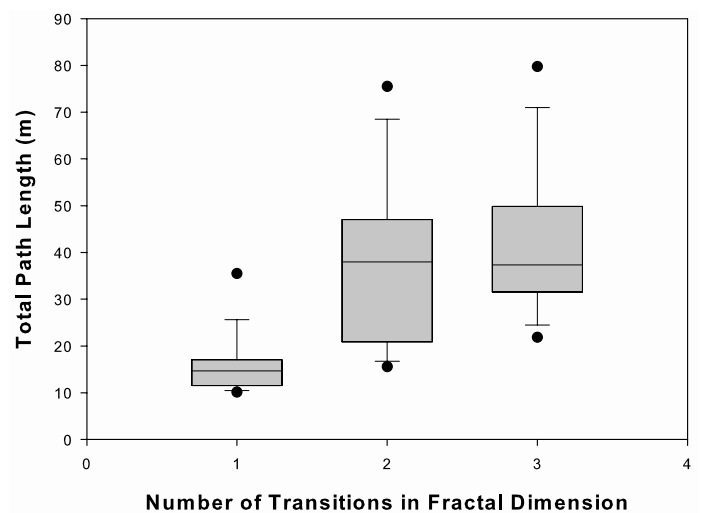

Figure 7. A box-plot summarizing the fractal-analysis results: the number of transitions in D, per path, was significantly correlated with the total path length. 


\subsection{Relationships between Path Variables and Habitat Features}

Most movement metrics were weakly, but significantly, associated with macrohabitat variables (Table 2). A few exceptions were the location of first transitions (association with the evenness of non-living things; $r=0.38 ; p=0.03$ ) and the variance of the average cosine among turning angles (association with soil humidity; $r=-0.43 ; p=0.02$ ). Interestingly, locations of the second and third transitions were associated with macrohabitat variables exclusively. The mean cosine of turning angles was also marginally associated with the evenness of non-living things $(r=-0.32 ; p=0.08)$. PCA of the microhabitat variables yielded three PC axes that cumulatively explained $69.6 \%$ of the variability in microhabitats. PCA of the macrohabitat variables also resulted in three PC axes that together explained $70.5 \%$ of the variation in macrohabitats. When micro and macro habitat variables were grouped together, the resulting PCA indicated significant differences between the study sites. Stepwise multiple regression analysis did not improve the results obtained with correlation analysis for any movement metric. The rankings of the habitat classes, according to habitat preference, were significantly different from one another (Hotellings $\mathrm{T}^{2}=59.94, \mathrm{~F}=3.16, n=32, p<$ 0.05 ) (Figure 8). Tall trees were found to be preferred significantly more than any other habitat feature followed by logs. Small shrubs, herbs, and small trees were significantly less preferred than other habitat classes.

Table 2. Relationships between movement metrics and habitat characteristics along movement paths of eastern chipmunks collected during this study. Only associations that are significant at $\mathrm{p}<0.10$ are shown in this table. Movement metrics included in this table are: A tortuosity factor, $\xi$ (see Equation (1)), $R_{g} / \mathrm{TBL}$, where $R_{g}$ is the radius of gyration and TPL is the total path length, LW $\alpha$ is the Lévy Walk model exponent $\alpha$ (Equation (8)), and T1, T2, and T3 identify three spatial scales where there were transitions in movement behavior. Principal component axes describing macrohabitat features are: "PC1 $1_{\text {Macro" }}$ is strongly associated with the density of large, medium and small trees; "PC2 $2_{\text {Macro" }}$ is strongly associated with canopy cover and the diversity of trees community; and "PC3Macro" is strongly associated with the circumference of trees and the evenness of tree species. " $r$ " is the Pearson correlation coefficient, " $p$ " is the probability and " $n$ " is the sample size.

\begin{tabular}{|c|c|c|c|c|c|c|c|c|}
\hline Habitat Metric & Tortuosity Factor, $\xi$ & $\mathrm{R}_{\mathrm{g}} / \mathrm{TPL}$ & LWa & $\mathrm{T} 1$ & $\mathrm{~T} 2$ & T3 & D2 & $\mathrm{D}_{3}$ \\
\hline & $r=0.36$ & 0.33 & & & 0.45 & & -0.33 & -0.41 \\
\hline \multirow[t]{3}{*}{ Trees circumference } & $p=0.04$ & $p=0.06$ & & & $p=0.04$ & & $p=0.07$ & $p=0.07$ \\
\hline & $n=32$ & $n=32$ & & & $n=21$ & & $n=31$ & $n=20$ \\
\hline & & & & & 0.56 & -0.54 & & \\
\hline \multirow[t]{3}{*}{ Dead trees density } & & & & & $p<0.01$ & $p=0.05$ & & \\
\hline & & & & & $n=21$ & $n=8$ & & \\
\hline & & & -0.36 & & 0.43 & -0.57 & & \\
\hline \multirow[t]{3}{*}{ Small trees density } & & & $p=0.05$ & & $p=0.05$ & $p=0.04$ & & \\
\hline & & & $n=32$ & & $n=21$ & $n=8$ & & \\
\hline & & & & & 0.42 & & & \\
\hline \multirow[t]{2}{*}{ Large trees density } & & & & & $p=0.06$ & & & \\
\hline & & & & & $n=21$ & & & \\
\hline \multirow[t]{2}{*}{ Habitat Metric } & Tortuosity Factor, $\xi$ & $\mathrm{R}_{\mathrm{g}} / \mathrm{TPL}$ & LWa & $\mathrm{T} 1$ & $\mathrm{~T} 2$ & T3 & D2 & $\mathrm{D}_{3}$ \\
\hline & & & & & & -0.53 & & \\
\hline \multirow[t]{2}{*}{ Logs density } & & & & & & $p=0.06$ & & \\
\hline & & & & & & $n=13$ & & \\
\hline
\end{tabular}


Continued

\begin{tabular}{|c|c|c|c|c|c|c|}
\hline & -0.42 & -0.32 & & & & \\
\hline \multirow[t]{3}{*}{ Canopy cover } & $p=0.02$ & $p=0.07$ & & & & \\
\hline & $n=32$ & $n=32$ & & & & \\
\hline & & & & & 0.49 & -0.63 \\
\hline \multirow[t]{3}{*}{$\mathrm{PCl}_{\text {Macro }}$} & & & & & $p=0.03$ & $p=0.04$ \\
\hline & & & & & $n=19$ & $n=8$ \\
\hline & -0.35 & & & & & \\
\hline \multirow[t]{3}{*}{ PC2 ${ }_{\text {Macro }}$} & $p=0.06$ & & & & & \\
\hline & $n=29$ & & & & & \\
\hline & & & 0.39 & 0.40 & & \\
\hline \multirow[t]{2}{*}{ PC3 ${ }_{\text {Macro }}$} & & & $p=0.04$ & $p=0.03$ & & \\
\hline & & & $n=29$ & $n=29$ & & \\
\hline
\end{tabular}

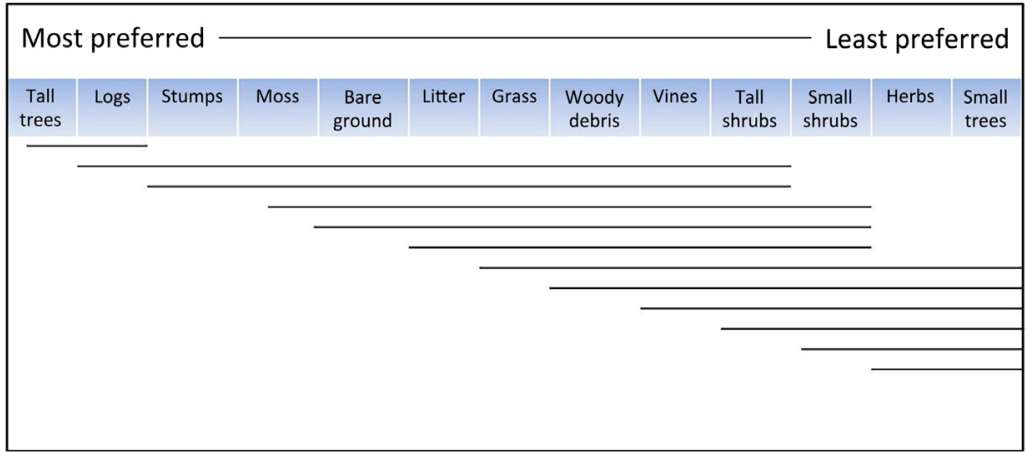

Figure 8. Relationships among the classes of habitat features from a habitat preference analysis for eastern chipmunks. Habitat classes sharing a common underline are not significantly different.

\section{Discussion}

In this study, we examined the movement paths of the eastern chipmunk in four landscapes of varying levels of habitat fragmentation on Prince Edward Island, Canada. All of the 32 paths exhibited scale-dependent changes in movement behaviour. Although there were statistical differences between the four landscapes in terms of the movement metrics analyzed in this study, these differences were relatively weak and, overall, the 32 paths exhibited similar scale-dependent changes in movement behaviour. In particular, at smaller spatial scales, $<2 \mathrm{~m}$, the movement did agree with the CRW model as demonstrated by the MSND graphs and the convergence of the fractal $D$ to 1 . At larger temporal and spatial scales, the MSNDs exceeded the CRW-model predictions demonstrating super-diffusive movement behaviour. As we did address potential autocorrelation issues here, which can confound CRWs with LWs [72], we are reasonably confident that the LW model better described the movement patterns over all spatial scales, as the scaling exponents for all of the four landscapes consistently fell within the predicted regimes (Equations (2.8) and (2.9)). In the context of optimal foraging theory, the LW model describes an efficient way for animals to maximize fitness (i.e., obtain the most benefit (food resources) for the lowest cost (energy spent)) in resource-poor areas. By occasionally making larg- 
er-length moves, a Lévy walker can cover greater areas per unit time and hence, in principle, minimize the amount of energy expended while searching for resources.

To gain greater insight into the movement behaviour, it is important to explore possible relationships between the movement patterns and certain habitat features at different spatial scales (e.g., [36] [43]). Our fractal analyses showed that all of the movement paths examined in this study presented at least one, often 2 - 3, transition points in the fractal $D$ that could be associated with changes in movement behaviour in response to habitat features occurring at different spatial scales. Most chipmunk paths showed a transition at $\sim 2 \mathrm{~m}$ that appeared to be negatively related to the density of small trees, suggesting that chipmunks were actively avoiding small trees. This hypothesis is corroborated by the habitat preference data where, in comparison with other classes of ground vegetation, small trees were among the least preferred habitat classes. At spatial scales in the vicinity of $5 \mathrm{~m}$, there was another transition in movement, followed by a slight decrease in $D$. This transition point was positively related to the large-tree density, which had a mean spacing of $\sim 5 \mathrm{~m}$. This result also complies with the habitat-selection data that indicated a strong preference for large trees. It may then be suggested that at larger spatial scales, on the order of $5 \mathrm{~m}$, the movement pattern of the eastern chipmunk is governed by the spatial distribution of large trees (i.e. the chipmunks were moving within patches of large trees with a mean spacing of $5 \mathrm{~m}$ ).

Hence, at spatial scales of $\sim 2 \mathrm{~m}$ there is good evidence that chipmunks are avoiding habitats with small trees and low-canopy cover and, at spatial scales of $\sim 5 \mathrm{~m}$, are selecting out areas with larger trees and denser canopy. The radius of gyration calculations supports these findings, where it was found that movement pathways were more compact in habitats with a greater overstory while more extensive in areas with low-canopy cover. However, as the Flory exponents were all greater than $3 / 5$ (indicating more directed or extensive movement patterns). This would suggest that chipmunks spend the majority of time either avoiding predators or seeking out resources at larger spatial scales. Our results here are similar to other studies of eastern chipmunk habitat use, where they have been found to be abundant in areas with a greater overstory density and lower amounts of ground foliage cover in Vermont [73], in forests with a greater density of trees in Illinois [74], and in fencerows with higher amounts of tree cover, tall shrubs, and litter/bare ground in Ottawa [56]. Habitats with denser canopy, and hence with a more open understory, may be preferred by eastern chipmunks based on their predator-avoidance strategies. A dense canopy cover probably provides the greatest amount of protection from avian predators. They are also a diurnal species and rely strongly on their sense of vision [75], so increases in the amount of understory vegetation could increase the difficulty in detecting predators [76] [77] [78]. Logs (which were found to be a highly preferred resource) may also allow them to increase predator detection, by permitting them to be slightly raised above the height of some of the ground vegetation. The role of 
habitat structure and visual impediments on the cost of foraging under predation risk has been widely noted in the literature [79] [80]. Reference [55] found that the locomotory behaviour of eastern chipmunks differed between more fragmented corridor habitats and continuous forest, with individuals spending more time in predator-vigilance behaviour in the more fragmented habitats. Therefore, predation risk may have an important influence on the behaviour of eastern chipmunks.

At larger spatial scales, greater than $5 \mathrm{~m}$, there was a decrease in $D$ suggesting a transition from more tortuous movement (reflective of the fractal dimension of the underlying vegetation pattern) to more directed-movement patterns. This result complies with the results of other studies of small-mammal movement (e.g., [81] [82] [83]). At these larger spatial scales, previous knowledge and spatial memory regarding their habitat may permit larger-scale directionality. The hypothesis that chipmunks have spatial memory is supported by other research (e.g., [82]). The researchers found that chipmunks that translocated across an unforested gap, outside of their home range, were generally able to find their way back and that more adults than juveniles found their way back. Homing, or long distance homeward orientation [83], was given as a probable explanation for this finding, implying that prior experience within the area by the adult chipmunks increased their success in returning home. Although the researchers could not discount other explanations (e.g., juveniles have greater motivation to disperse rather than to return home), the importance of prior knowledge of an area in successful homing by small mammals has been demonstrated in other studies [81] [83].

Eastern chipmunks are territorial individuals that defend a core area [50] [54]. Additionally, they tend to spend about three quarters of their time in the area within $25 \mathrm{~m}$ of their burrow entrance [51]. These traits may also add plausibility to the hypothesis that memory is likely to play an important role in their movement behaviour. They should have sufficient time to be able to develop internal maps of their core areas, and most likely recognize habitat characteristics in their core areas in order to more successfully defend these areas against conspecifics. Therefore, eastern chipmunks may possess both short-term memory about their previous movements, and memory of actions/events occurring over longer-time periods. A component of both long and short-term memory would be spatial memory that allows the chipmunks to know where they are in relation to other important objects (e.g., primary burrow and food caches).

Although there were statistically significant differences between the landscapes selected for this study, a key point to recognize is that the movement paths obtained in this study were at the forest-patch level and, hence, we were unable to examine movement patterns that covered the full extent of any given field-site at the landscape scale. Hence, although the effects of fragmentation may have had some indirect impact on movement behaviour in this study, we were unable to determine significant differences in movement patterns between 
landscapes. Thus, in order to examine the effect of habitat fragmentation at the landscape scale, improved tracking methods would need to be employed in order to obtain longer movement paths. However, fragmentation at the forest-patch scale may play an important role in affecting movement. For example, since the paths of the eastern chipmunks were more elongated in areas with low-canopy cover, which represent functionally fragmented regions, this type of habitat may be less preferred. In comparison with other small-animal movement studies, reference [84] found that in more fragmented habitats, prairie voles (Microtus ochrogaster) and deer mice moved greater distances. Their movements were at spatial scales that reflected daily movement, and therefore in fragmented habitats (which the authors viewed as unfavourable for these species) they were forced to travel farther distances to meet their daily foraging and other requirements.

\section{Conclusions}

In summary, our results clearly show that the movement patterns of eastern chipmunks are scale-dependent and strongly influenced by both innate behaviour and habitat features, agreeing with findings from other studies (e.g., [3] [11] [85]). One explanation for these findings is that chipmunk movement behaviour is regulated by daily activities within their home range, such as foraging, predator avoidance, and homing. At spatial scales less than $2 \mathrm{~m}$, chipmunks may be engaged in foraging activities within suitable habitat. At spatial scales on the order of $5 \mathrm{~m}$, chipmunks may be switching their movement in an effort to avoid predators in areas with small trees and low-canopy cover and move towards more favourable habitat, such as large trees with greater canopy cover. At even larger spatial scales, movement is more likely driven by longer-term memory and homing behaviour that is characterized by more directed-movement patterns.

It is interesting that, despite evidence for scale-dependent changes in movement behaviour, all of the movement data were well supported by the LW model-implying scale-invariant movement patterns. It is possible that scale-specific activities, including foraging and predator avoidance, are strongly influenced by the fractal distribution of resources across various spatial scales up to the forest-patch level. In a two-part study on spider monkeys [43] [86], it was demonstrated that primates could optimally search for fruits in a tropical forest under the assumption that they memorized the relative value of a given tree based on its fruit content and travel distance. Although the search strategy was a memory-driven, non-LW process, the resulting LW movement pattern that was generated could be explained by the self-similar distribution of tree sizes. Using a memory-enhanced, multiscaled, random-walk (MRW) model with site fidelity, reference [87] demonstrated that a LW pattern could also emerge in patchy, but non-fractal, landscapes. This important study illustrated how a model that balanced short-term and local ("tactical moves") with less frequent, but long- 
er-ranging travel ("strategic moves") could produce a scale-free space-use process-but not LW, due to memory dependence.

Other studies have also demonstrated that movement patterns characteristic of Lévy walks can surface from processes not related to optimal foraging [88] and may emerge from different types of non-Lévy search strategies [89]. For example, it has been demonstrated that composite Brownian Walks (CBW), consisting of a mixture of two or more simple random walks (SRW) (scale-specific strategies) can generate heavy-tailed power-law distributions of move lengths that look Lévy-like (scale free), but may be more efficient than the scale-free strange kinetics of LWs for foraging in patchy landscapes [44] [90] However, this type of emergent-school view of the origins of animal foraging has been contested by the evolutionary-school view that maintains that, in situations where a forager's information is limited to its immediate vicinity and resources are sparse, animals evolved to optimize their foraging success by adopting a LW search strategy. For example, using a reaction-diffusion algorithm, reference [41] explored the effects of landscape diversity on efficient search strategies and found that the LW model consistently presented the optimal solution within a wide range of landscapes (with landscapes varying in the level of fragmentation, heterogeneity, size and distribution of patches, target density, etc.). Hence, given the robustness of their findings, there is good evidence supporting an evolutionary origin for Lévy walks as a more general optimal search strategy (in contrast to specific search strategies based on detailed forager-habitat interaction models that give rise to Lévy-like patterns). In a recent review, reference [91] summarizes the "heated debate" between these two schools of thought, where it would appear that Lévy walk movement patterns are ubiquitous and are context-independent, whereas the underlying generative processes may be context-specific.

Based on our findings here for the eastern chipmunk, our data suggest that scale-specific movement strategies are employed as the chipmunks switch between different daily activities. Although we observe LW-like movement patterns, it is likely that such scale-free patterns are emerging due to both the fractal distribution of resources and cognitive mapping. As stated by reference [88], "Lévy walks emerge spontaneously and naturally from innate behaviours and innocuous responses to the environment but, if advantageous, then there could be selection against losing them". However, due to the fact that our evidence is indirect and we do not have first-hand behavioural observations, we cannot completely discount the possibility of LW-like processes at play, that has evolved over time, but that these movement patterns are modulated by specific walker-environment interactions that are (spatially and temporally) scale-dependent.

\section{Acknowledgements}

We thank Prince Edward Island National Park and the Department of Biology of the University of Prince Edward Island (UPEI) for access to their lands, and the 
following people for help in the field: E. Laurin, C. Knickle, E. Knox, and J. Mailhiot. This research was supported by an internal grant from UPEI, and discovery grants from the Natural Sciences and Engineering Research Council of Canada (NSERC) to S. Opps and M. Silva-Opps. Financial support for L. Hartling was also provided by NSERC through a graduate scholarship.

\section{Conflicts of Interest}

The authors declare no conflicts of interest regarding the publication of this paper.

\section{References}

[1] Wiens, J.A., Crist, T.O., With, K.A. and Milne, B.T. (1995) Fractal Patterns of Insect Movement in Microlandscape Mosaics. Ecology, 76, 663-666. https://doi.org/10.2307/1941226

[2] Avgar, T., Mosser, A., Brown, G.S. and Fryxell, J.M. (2013) Environmental and Individual Drivers of Animal Movement Patterns across a Wide Geographical Gradient. Journal of Animal Ecology, 82, 96-106. https://doi.org/10.1111/j.1365-2656.2012.02035.x

[3] Karelus, D.L., McCown, J.W., Scheick, B.K., van der Kerk, M., Bolker, B.M. and Oli, M.K. (2017) Effects of Environmental Factors and Landscape Features on Movement Patterns of Florida Black Bears. Journal of Mammalogy, 98, 1463-1478. https://doi.org/10.1093/jmammal/gyx066

[4] Morales, J.M., Moorcroft, P.R., Matthiopoulos, J., Frair, J.L., Kie, J.G., Powell, R.A., Merrill, E.H. and Haydon, D.T. (2010) Building the Bridge between Animal Movement and Population Dynamics. Philosophical Transactions Royal Society B, 365, 2289-2301. https://doi.org/10.1098/rstb.2010.0082

[5] Wiens, J.A., Crist, T.O. and Milne, B.T. (1993) On Quantifying Insect Movements. Environmental Entomology, 22, 709-715. https://doi.org/10.1093/ee/22.4.709

[6] With, K.A. (1994) Using Fractal Analysis to Assess How Species Perceive Landscape Structure. Landscape Ecology, 9, 25-36. https://doi.org/10.1007/BF00135076

[7] Lima, S.L. and Zollner, P.A. (1996) Towards a Behavioral Ecology of Ecological Landscapes. Trends in Ecology and Evolution, 11, 131-135.

https://doi.org/10.1016/0169-5347(96)81094-9

[8] Gillis, E.A., and Nams, V.O. (1998) How Red-Backed Voles (Clethrionomys gapperi pallescens) Find Habitats. Canadian Journal of Zoology, 76, 791-794. https://doi.org/10.1139/z98-017

[9] Zollner, P.A. and Lima, S.L. (1999) Search Strategies for Landscape-Level Interpatch Movements. Ecology, 80, 1019-1030. https://doi.org/10.1890/0012-9658(1999)080[1019:SSFLLI]2.0.CO;2

[10] Edwards, M.A., Forbes, G.J. and Bowman, J. (2001) Fractal Dimension of Ermine, Mustela erminea (Carnivora: Mustelidae), Movement Patterns as an Indicator of Resource Use. Mammalia, 65, 220-225.

[11] Morales, J.M. (2002) Behavior at Habitat Boundaries Can Produce Leptokurtic Movement Distributions. American Naturalist, 160, 531-538.

https://doi.org/10.1086/342076

[12] MacDonald, W.R. and St. Clair, C.C. (2004) The Effects of Artificial and Natural Barriers on the Movement of Small Mammals in Banff National Park, Canada. Oi- 
kos, 105, 397-407. https://doi.org/10.1111/j.0030-1299.2004.12640.x

[13] Crist, T.O., Guertin, D.S., Wiens, J.A. and Milne, B.T. (1992) Animal Movement in Heterogenous Landscapes: An Experiment with Eleodes Beetles in Shortgrass Prairie. Functional Ecology, 6, 536-544. https://doi.org/10.2307/2390050

[14] Crist, T.O. and Wiens, J.A. (1994) Scale Effects of Vegetation on Forager Movement and Seed Harvesting by Ants. Oikos, 69, 37-46. https://doi.org/10.2307/3545281

[15] Brillhart, D.B. and Kaufman, D.W. (1991) Influence of Illumination and Surface Structure on Space Use by Prairie Mice (Peromyscus maniculatus bairdii). Journal of Mammalogy, 72, 764-768. https://doi.org/10.2307/1381840

[16] Thompson, S.D. (1982) Microhabitat Utilization and Foraging Behavior of Bipedal and Quadrupedal Heteromyid Rodents. Ecology, 63, 1313-1321. https://doi.org/10.2307/1938859

[17] Vásquez, R.A., Ebensperger, L.A. and Bozinovic, F. (2002) The Influence of Habitat on Travel Speed, Intermittent Locomotion, and Vigilance in a Diurnal Rodent. Behavioral Ecology, 13, 182-187. https://doi.org/10.1093/beheco/13.2.182

[18] Schooley, R.L., Sharpe, P.B. and Van Horne, B. (1996) Can Shrub Cover Increase Predation Risk for a Desert Rodent? Canadian Journal of Zoology, 74, 157-163. https://doi.org/10.1139/z96-020

[19] Benhamou, S. (1990) An Analysis of Movements of the Wood Mouse Apodemus sylvaticus in Its Home Range. Behavioural Processes, 22, 235-250. https://doi.org/10.1016/0376-6357(91)90097-J

[20] Stapp, P. and Van Horne, B. (1997) Response of Deer Mice (Peromyscus maniculatus) to Shrubs in Shortgrass Prairie: Linking Small-Scale Movements and the Distribution of Individuals. Functional Ecology, 11, 644-651.

https://doi.org/10.1046/j.1365-2435.1997.00133.x

[21] With, K.A. (1994) Ontogenetic Shifts in How Grasshoppers Interact with Landscape Structure: An Analysis of Movement Patterns. Functional Ecology, 8, 477-485. https://doi.org/10.2307/2390072

[22] Abrahams, M.V. (1986) Patch Choice under Perceptual Constraints: A Cause for Departures from an Ideal Free Distribution. Behavioral Ecology and Sociobiology, 19, 409-415. https://doi.org/10.1007/BF00300543

[23] Delgado, M., Penteriani, V., Revilla, E. and Nams, V.O. (2010) The Effect of Phenotypic Traits and External Cues on Natal Dispersal Movements. Journal of Animal Ecology, 79, 620-632. https://doi.org/10.1111/j.1365-2656.2009.01655.x

[24] Katz, N. and Scharf, I. (2018) Habitat Geometry and Limited Perceptual Range Affect Habitat Choice of a Trap-Building Predator. Behavioral Ecology, 29, 958-964. https://doi.org/10.1093/beheco/ary046

[25] Schooley, R.L. and Wiens, J.A. (2003) Finding Habitat Patches and Directional Connectivity. Oikos, 102, 559-570. https://doi.org/10.1034/j.1600-0706.2003.12490.x

[26] Chapuis, N., Durup, M. and Thinus-Blanc, C. (1987) The Role of Exploratory Experience in a Shortcut Task by Golden Hamsters (Mesocricetus auratus). Animal Learning and Behavior, 15, 174-178. https://doi.org/10.3758/BF03204960

[27] Atkinson, R.P.D., Rhodes, C.J., Macdonald, D.W. and Anderson, R.M. (2002) Scale-Free Dynamics in the Movement Patterns of Jackals. Oikos, 98, 134-140. https://doi.org/10.1034/j.1600-0706.2002.980114.x

[28] Sheppe, W. (1965) Dispersal by Swimming in Peromyscus leucopus. Journal of Mammalogy, 46, 336-337. https://doi.org/10.2307/1377863 
[29] Lemen, C.A. and Freeman, P.W. (1985) Tracking Mammals with Flourescent Pigments: A New Technique. Journal of Mammalogy, 66, 134-136. https://doi.org/10.2307/1380966

[30] Thibault, A. and Bovet, J. (1999) Homing Strategy of the Eastern Chipmunk, Tamias striatus (Mammalia: Rodentia): Validation of the Critical Distance Model. Ethology, 105, 73-82. https://doi.org/10.1111/j.1439-0310.1999.tb01221.x

[31] Barnum, S.A., Manville, C.J., Tester, J.R. and Carmen, W.J. (1992) Path Selection by Peromyscus maniculatus in the Presence and Absence of Vegetative Cover. Journal of Mammalogy, 73, 797-801. https://doi.org/10.2307/1382198

[32] Luque-Larena, J.J., López, P. and Gosálbez, J. (2002) Microhabitat Use by the Snow Vole Chionomys nivalis in Alpine Environments Reflects Rock-Dwelling Preferences. Canadian Journal of Zoology, 80, 36-41. https://doi.org/10.1139/z01-197

[33] Stapp, P. (1997) Habitat Selection by an Insectivorous Rodent: Patterns and Mechanisms across Multiple Scales. Journal of Mammalogy, 78, 1128-1143. https://doi.org/10.2307/1383055

[34] Kareiva, P.M. and Shigesada, N. (1983) Analyzing Insect Movement as a Correlated Random Walk. Oecologia, 56, 234-238. https://doi.org/10.1007/BF00379695

[35] Turchin, P. (1998) Quantitative Analysis of Movement: Measuring and Modeling Population Redistribution in Animals and Plants. Sinauer Associates Inc., Sunderland.

[36] Bartumeus, F., Peters, F., Pueyo, S., Marrasé, C. and Catalan, J. (2003) Helical Lévy Walks: Adjusting Searching Statistics to Resource Availability in Microzooplankton. Proceedings of the National Academy of Sciences, 100, 12771-12775. https://doi.org/10.1073/pnas.2137243100

[37] Dicke, M. and Burrough, P.A. (1988) Using Fractal Dimensions for Characterizing Tortuosity of Animal Trails. Physiological Entomology, 13, 393-398. https://doi.org/10.1111/j.1365-3032.1988.tb01122.x

[38] Wiens, J.A., Schooley, R.L. and Weeks Jr., R.D. (1997) Patchy Landscapes and Animal Movements: Do Beetles Percolate? Oikos, 78, 257-264. https://doi.org/10.2307/3546292

[39] Schuster, F.L. and Levandowsky, M. (1996) Chemosensory Random Movement and Responses to Chemical Signals. Journal of Eukaryotic Microbiology, 43, 150-158. https://doi.org/10.1111/j.1550-7408.1996.tb04496.x

[40] Viswanathan, G.M., Afanasyev, V., Buldyrev, S.V., Murphy, E.J., Prince, P.A. and Stanley, H.E. (1996) Lévy Flight Search Patterns of Wandering Albatrosses. Nature, 381, 413-415. https://doi.org/10.1038/381413a0

[41] Wosniack, M.E., Santos, M.C., Raposo, E.P., Viswanathan, G.M. and Da Luz, M.G.E. (2017) The Evolutionary Origins of Lévy Walk Foraging. PLoS Computational Biology, 13, e1005774. https://doi.org/10.1371/journal.pcbi.1005774

[42] Buldyrev, S.V., Havlin, S., Kazakov, A.Y., Da Luz, M.G.E., Raposo, E.P., Stanley, H.E. and Viswanathan, G.M. (2001) Average Time Spent by Lévy Flights and Walks on an Interval with Absorbing Boundaries. Physical Review E, 64, 041108 https://doi.org/10.1103/PhysRevE.64.041108

[43] Ramos-Fernández, G., Mateos, J.L., Miramontes, O., Cocho, G., Larralde, H. and Ayala-Orozco, B. (2004) Lévy Walk Patterns in the Foraging Movements of Spider Monkeys (Ateles geoffroyi). Behavioral Ecology and Sociobiology, 55, 223-230. https://doi.org/10.1007/s00265-003-0700-6

[44] Benhamou, S. (2007) How Many Animals Really Do the Lévy Walk? Ecology, 88, 
1962-1969. https://doi.org/10.1890/06-1769.1

[45] Mandelbrot, B. (1967) How Long Is the Coast of Britain? Statistical Self-Similarity and Fractal Dimension. Science, 156, 636-638.

https://doi.org/10.1126/science.156.3775.636

[46] Turchin, P. (1996) Fractal Analysis of Animal Movement: A Critique. Ecology, 77, 2086-2090. https://doi.org/10.2307/2265702

[47] Halley, J.M., Hartley, S., Kallimanis, A.S., Kunin, W.F., Lennon, J.J. and Sgardelis, S.P. (2004) Use and Abuses of Fractal Methodology in Ecology. Ecology Letters, 7, 254-271. https://doi.org/10.1111/j.1461-0248.2004.00568.X

[48] Turner, M.G., Dale, V.H. and Gardner, R.H. (1989) Predicting across Scales: Theory Development and Testing. Landscape Ecology, 3, 245-252. https://doi.org/10.1007/BF00131542

[49] Henein, K., Wegner, J. and Merriam, G. (1998) Population Effects of Landscape Model Manipulation on Two Behaviourally Different Woodland Small Mammals. Oikos, 81, 168-186. https://doi.org/10.2307/3546479

[50] Bowers, M.A., Welch, D.N. and Carr, T.G. (1990) Home Range Size Adjustments by the Eastern Chipmunk, Tamias striatus, in Response to Natural and Manipulated Water Availability. Canadian Journal of Zoology, 68, 2016-2020. https://doi.org/10.1139/z90-284

[51] Elliot, L. (1978) Social Behaviour and Foraging Ecology of the Eastern Chipmunk (Tamias striatus) in the Adirondack Mountains. Smithsonian Contributions of Zoology, 265, 1-107.

[52] Forsyth, D.J. and Smith, D.A. (1973) Temporal Variability in Home Ranges of Eastern Chipmunks (Tamias striatus) in a South-Eastern Ontario Woodlot. American Midland Naturalist, 90, 107-117. https://doi.org/10.2307/2424271

[53] Hackett, D.G. and Trevor-Deutsch, B. (1982) An Evaluation of Several Grid-trapping Methods by Comparison with Radio-Telemetry in a Home Range Study of the Eastern Chipmunk (Tamias striatus). Biotelemetry and Patient Monitoring, 9, 213-226.

[54] Lacher, T.E., Jr. and Mares, M. (1996) Availability of Resources and Use of Space in Eastern Chipmunks, Tamias striatus. Journal of Mammalogy, 77, 833-849. https://doi.org/10.2307/1382689

[55] Mahan, C.G. and Yahner, R.H. (1999) Effects of Forest Fragmentation on Behaviour Patterns in the Eastern Chipmunk (Tamias striatus). Canadian Journal of Zoology, 77, 1991-1997. https://doi.org/10.1139/z99-174

[56] Bennett, A.F., Henein, K. and Merriam, G. (1994) Corridor Use and the Elements of Corridor Quality: Chipmunks and Fencerows in a Farmland Mosaic. Biological Conservation, 68, 155-165. https://doi.org/10.1016/0006-3207(94)90347-6

[57] Silva, M., Hartling, L.A. and Opps, S.B. (2005) Small Mammals in Agricultural Landscapes of Prince Edward Island (Canada): Effects of Habitat Characteristics at Three Different Spatial Scales. Biological Conservation, 126, 556-568. https://doi.org/10.1016/j.biocon.2005.07.007

[58] Boonstra, R. and Craine, I.T.M. (1986) Natal Nest Location and Small Mammal Tracking with a Spool and Line Technique. Canadian Journal of Zoology, 64, 1034-1036. https://doi.org/10.1139/z86-153

[59] Anderson, T.J.C., Berry, A.J., Amos, J.N. and Cook, J.M. (1988) Spool-and-Line Tracking of the New Guinea Spiny Bandicoot, Echymipera kalubu, (Marsupialia, Peramelidae). Journal of Mammalogy, 69, 114-120. 
https://doi.org/10.2307/1381754

[60] Nams, V.O. (1996) The Vfractal: A New Estimator for Fractal Dimension of Animal Movement Paths. Landscape Ecology, 11, 289-297.

https://doi.org/10.1007/BF02059856

[61] With, K.A., Cadaret, S.J. and Davis, C. (1999) Movement Responses to Patch Structure in Experimental Fractal Landscapes. Ecology, 80, 1340-1353. https://doi.org/10.1890/0012-9658(1999)080[1340:MRTPSI]2.0.CO;2

[62] Doi, M. and Edwards, S.F. (1999) The Theory of Polymer Dynamics. Oxford University Press, New York.

[63] Flory, P. (1953) Principles of Polymer Chemistry. Cornell University Press, New York.

[64] Nams, V.O. and Bourgeois, M. (2004) Fractal Analysis Measures Habitat Use at Different Spatial Scales: An Example with American Marten. Canadian Journal of Zoology, 82, 1738-1747. https://doi.org/10.1139/z04-167

[65] Wiens, J.A. and Milne, B.T. (1989) Scaling of Landscapes in Landscape Ecology, or, Landscape Ecology from a Beetles Perspective. Landscape Ecology, 3, 87-96. https://doi.org/10.1007/BF00131172

[66] Cleveland, W.S. (1979) Robust Locally Weighted Regression and Smoothing Scatterplots. Journal of the American Statistical Association, 74, 829-836. https://doi.org/10.1080/01621459.1979.10481038

[67] Sugihara, G. and May, R.M. (1990) Applications of Fractals in Ecology. Trends in Ecology and Evolution, 5, 79-86. https://doi.org/10.1016/0169-5347(90)90235-6

[68] Johnson, R.A. and Wichern, D.W. (1992) Applied Multivariate Statistical Analysis. 5th Edition. Prentice Hall, Inc., New York.

[69] Johnson, D.H. (1980) The Comparison of Usage and Availability Measurements for Evaluating Resource Preference. Ecology, 61, 65-71.

https://doi.org/10.2307/1937156

[70] Waller, R.A. and Duncan, D.B. (1969) A Bayes Rule for the Symmetric Multiple Comparisons Problems. Journal of the American Statistical Association, 64, 1484-1503. https://doi.org/10.1080/01621459.1969.10501073

[71] Newman, M.E.J. (2005) Power Laws, Pareto Distributions and Zipf's Law. Contemporary Physics, 46, 323-351. https://doi.org/10.1080/00107510500052444

[72] Reynolds, A.M. (2010) Bridging the Gulf between Correlated Random Walks and Lévy Walks: Autocorrelation as a Source of Lévy Walk Movement Patterns. Journal of the Royal Society Interface, 7, 1753-1758. https://doi.org/10.1098/rsif.2010.0292

[73] Brooks, R.T., Smith, H.R. and Healy, W.M. (1998) Small Mammal Abundance at Three Elevations on a Mountain in Central Vermont, USA: A Sixteen Year Record. Forest Ecology and Management, 110, 181-193. https://doi.org/10.1016/S0378-1127(98)00289-8

[74] Schmid-Holmes, S. and Drickamer, L.C. (2001) Impact of Forest Patch Characteristics on Small Mammal Communities: A Multivariate Approach. Biological Conservation, 99, 293-305. https://doi.org/10.1016/S0006-3207(00)00195-6

[75] Doutt, J.K., Heppenstall, C.A., and Guilday, J.E. (1977) Mammals of Pennsylvania. Carnegie Institute, Pittsburgh.

[76] Carey, H.V. and Moore, P. (1986) Foraging and Predation Risk in Yellow-Bellied Marmots. American Midland Naturalist, 116, 267-275.

https://doi.org/10.2307/2425734

[77] Metcalfe, N.B. (1984) The Effects of Habitat on the Vigilance of Shore-Birds: Is Vi- 
sibility Important? Animal Behaviour, 32, 981-985. https://doi.org/10.1016/S0003-3472(84)80210-9

[78] Sharpe, P.B. and Van Horne, B. (1998) Influence of Habitat on the Behaviour of Townsend's Ground Squirrels (Spermophilus townsendii). Journal of Mammalogy, 79, 906-918. https://doi.org/10.2307/1383098

[79] Brown, J.S. and Kotler, B.P. (2004) Hazardous Duty Pay and the Foraging Cost of Predation. Ecology Letters, 7, 999-1014. https://doi.org/10.1111/j.1461-0248.2004.00661.x

[80] Whelan, C.J. and Maina, G.G. (2005) Effects of Season, Understory Vegetation Density, Habitat Edge and Tree Diameter on Patch-Use by Bark-Foraging Birds. Functional Ecology, 19, 529-536. https://doi.org/10.1111/j.1365-2435.2005.00996.x

[81] Bovet, J. (1984) Strategies of Homing Behavior in the Red Squirrel, Tamiasciurus hudsonicus. Behavioural Ecology and Sociobiology, 16, 81-88. https://doi.org/10.1007/BF00293107

[82] Bowman, J. and Fahrig, L. (2002) Gap Crossing by Chipmunks: An Experimental Test of Landscape Connectivity. Canadian Journal of Zoology, 80, 1556-1561. https://doi.org/10.1139/z02-161

[83] Joslin, J.K. (1977) Rodent long Distance Orientation ("Homing"). Advances in Ecological Research, 10, 63-89. https://doi.org/10.1016/S0065-2504(08)60234-2

[84] Diffendorfer, J.E., Gaines, M.S. and Holt, R.D. (1995) Habitat Fragmentation and Movements of Three Small Mammals (Sigmodon, Microtus, and Peromyscus). Ecology, 76, 827-839. https://doi.org/10.2307/1939348

[85] Guarire, E., Anderson, J.J. and Zabel, R.W. (2009) Incorporating Population Heterogeneity into Analysis of Animal Dispersal and Movement. Ecology, 90, 2233-2242.https://doi.org/10.1890/08-0359.1

[86] Boyer, D., Ramos-Fernández, G., Miramontes, O., Cocho, G., Larralde, H., Ramos, H. and Rojas, F. (2006) Scale-Free Foraging by Primates Emerges from their Interaction with a Complex Environment. Proceedings of the Royal Society B, 273, 1743-1750. https://doi.org/10.1098/rspb.2005.3462

[87] Gautestad, A.O. and Mysterud, I. (2005) Intrinsic Scaling Complexity in Animal Dispersion and Abundance. American Naturalist, 165, 44-55.

https://doi.org/10.1086/426673

[88] Reynolds, A.M. (2015) Liberating Lévy Walk Research from the Shackles of Optimal Foraging. Physics of Life Reviews, 14, 59-83. https://doi.org/10.1016/j.plrev.2015.03.002

[89] Reynolds, A.M. (2013) Selection Pressures Give Composite Correlated Random Walks Lévy Walk Characteristics. Journal of Theoretical Biology, 332, 117-122. https://doi.org/10.1016/j.jtbi.2013.04.035

[90] Benhamou, S. and Collet, J. (2015) Ultimate Failure of the Lévy Foraging Hypothesis: Two-Scale Searching Strategies Outperform Scale-Free Ones Even When Prey Are Scarce and Cryptic. Journal of Theoretical Biology, 387, 221-227. https://doi.org/10.1016/j.jtbi.2015.09.034

[91] Reynolds, A.M. (2018) Current Status and Future Directions of Lévy Walk Research. The Company of Biologists (Meeting Review), 7, bio030106.

https://doi.org/10.1242/bio.030106

[92] Krebs, C.J. (1999) Ecological Methodology. 2nd Edition, Benjamin-Cummings, Menlo Park. 